Devel opment of ther noel ect ri c mat er i al s usi ng hi gh- pressure synt hesi s techni que

\begin{tabular}{|l|l|}
\hline 著者 & SEK NE Chi hi ro, MORI Yoshi hi sa \\
\hline $\begin{array}{l}\text { j our nal or } \\
\text { publ i cat i on ti tl e }\end{array}$ & Japanese Journal of Appl i ed Physi cs \\
\hline vol une & 56 \\
\hline number & $5 S 3$ \\
\hline page $r$ ange & 05FA09 \\
\hline year & $2017-04$ 13 \\
\hline URL & ht t p: //hdl . handl e. net /10258/00009677 \\
\hline
\end{tabular}




\title{
Development of thermoelectric materials using high-pressure synthesis technique
}

\author{
Chihiro Sekine ${ }^{1 *}$ and Yoshihisa Mori ${ }^{2 *}$ \\ ${ }^{1}$ Muroran Institute of Technology, Muroran, Hokkaido 050-8585, Japan \\ ${ }^{2}$ Okayama University of Science, Okayama 700-0005, Japan \\ *E-mail: sekine@mmm.muroran-it.ac.jp; mori@das.ous.ac.jp
}

Thermoelectric materials, which convert heat energy directly into electricity, play an important role in providing globally sustainable energy. In recent years, much effort has been exerted in improving thermoelectric efficiency using various modern synthesis methods. The high-pressure synthesis method has various advantages such as the possibility of synthesizing new materials with impossible structures and compositions at ambient pressure. In this review, we will focus on exploring new compounds using a high-pressure apparatus. The high-pressure synthesis and thermoelectric measurement technique will be discussed. In addition, in-situ X-ray diffraction experiments under high temperature and high pressure to determine the conditions for high-pressure synthesis will be discussed. Finally, the thermoelectric properties of several compounds (skutterudites and magnesium silicide) prepared under high pressure will be reviewed. 


\section{Introduction}

Thermoelectric (TE) materials that can directly convert heat to electrical energy are expected for the application of an environmentally-friendly power generation system with the advantages of no pollutants, small size, and availability in a wide temperature range. ${ }^{1)}$ The potential of a material for TE applications is determined by the dimensionless figure of merit $Z T$ given by a combination of the electrical conductivity $\sigma$, the thermal conductivity $\kappa$, the Seebeck coefficient $S$, and the absolute temperature $T$, namely, $Z T=T \sigma S^{2} / \kappa$. The thermal conductivity $\kappa$ has both electronic and lattice contributions ( $\kappa_{\mathrm{E}}$ and $\kappa_{\mathrm{L}}$ ) and is given by $\kappa_{\mathrm{E}}+\kappa_{\mathrm{L}}{ }^{2}$ ) For a broad range of commercial applications, ZT should be greater than unity. Finding materials with higher $Z T$ values is essential for power generation application. In recent years, much effort has been exerted in improving TE efficiency using various modern synthesis methods such as nanostructural engineering and high-pressure synthesis. The high-pressure synthesis method has various advantages as follows: it is possible to achieve a reaction between elements with large differences in vapor pressure in closed space without changing composition. Using the difference in ion compressibility, the synthesis of compounds with a crystal structure or composition, which is not achieved at ambient pressure, is possible. We review recent advances in exploring new compounds using a high-pressure apparatus.

\section{High-pressure synthesis technique and measurement of physical properties}

In the following sections an overview will be given on high-pressure synthesis techniques including piston cylinder equipment and a multi-anvil apparatus. The multi-anvil apparatus is classified depending on the anvil system in two types: Kawai-type apparatus (multi-anvil 6-8 system) and cubic anvil apparatus. In addition, in-situ synchrotron X-ray diffraction experiments using a cubic anvil apparatus (multi-anvil 6-6 system) will also be discussed. Furthermore, thermoelectric measurement will be introduced.

\subsection{Piston cylinder equipment}

The piston cylinder equipment is a conventional high-pressure apparatus, especially used for low-pressure experiments up to several GPa. Pressure is determined using $P=\eta F / A$, where $F$ is the applied force, $A$ is the effective area of the cylinder, and $\eta$ is the correction coefficient of friction between the piston and the cylinder. The piston and cylinder are 
made of tungsten carbide, and the cylinder is supported by a clamping ring to minimize elastic deformation. Figure 1 shows the cell assembly for the high-pressure apparatus with a 3/4" diameter piston. The sample container consists of a graphite heater, a Pyrex sleeve, and a talc sleeve. Starting materials are put in a crucible made of boron nitride (BN). The crucible is inserted into the graphite sleeve and fixed by the upper and lower MgO plugs.

\subsection{Cubic-anvil type high-pressure apparatus}

The cubic-anvil apparatus is classified depending on the anvil system into two types: wedge-type and DIA-type. For the wedge-type apparatus, the upper and lower stages consist of three anvils that slide on the wedge formed in shallow V-shaped grooves. ${ }^{3)}$ The anvil movement is completely synchronized by means of the wedge system. For the DIA-type apparatus (Fig. 2), ${ }^{4)}$ the upper and lower stages have one anvil each, and so do the four sliding (side) blocks. The side blocks slide on the upper and lower guide blocks. For both types of apparatus, the anvils with a top-squared face are made of tungsten carbide. The sample cell assembly of the wedge-type apparatus is almost the same as that of the DIA-type one. ${ }^{3)}$ Figure 3 shows an example of the cell assembly. ${ }^{4)}$ The sample container made of pyrophyllite is formed into a cube. The starting materials are put in a crucible made of BN. The crucible with a graphite heater is inserted into the pyrophyllite cube.

\subsection{Kawai-type high-pressure apparatus}

In the Kawai-type multi-anvil apparatus (6-8 system, Fig. 4), ${ }^{4)}$ sample pressure is generated by successive compression: (1) A hydraulic ram drives six first-stage anvils. (2) The six first-stage anvils compress eight second-stage anvils. (3) The second-stage anvils compress an octahedral cell assembly. Tungsten-carbide cubes with a truncated edge are used as the second-stage anvils. The sample cell assembly is similar to that used for the cubic anvil apparatus (Fig. 5). ${ }^{4,5)}$ The sample container, made of magnesia $(\mathrm{MgO}+5 \%$ $\mathrm{Cr}_{2} \mathrm{O}_{3}$ ), was transformed into an octahedron. The starting materials were put in a crucible made of $\mathrm{BN}$. The crucible, with a graphite heater surrounded with a zirconia $\left(\mathrm{ZrO}_{2}\right)$ thermal insulator, was inserted into the magnesia octahedron.

\subsection{In-situ X-ray diffraction experiment}

Before the high-pressure synthesis, it is effective to investigate the synthesis processes of target compounds at high pressures and high temperatures by in-situ X-ray diffraction 
measurements using synchrotron radiation. By a series of the measurements, we can obtain the optimum conditions for synthesizing the target compounds under high pressure. In-situ X-ray diffraction patterns are generally taken by an energy-dispersive method using synchrotron radiation and a solid-state detector. As one example, the system at Photon Factory (PF) in the High Energy Accelerator Research Organization (KEK; Tsukuba, Japan) is described. ${ }^{6,7)}$ High pressure is applied using multi-anvil assembly 6-6 (MA6-6) with a cubic-anvil high-pressure apparatus, the MAX80 system, installed at the beamline AR-NE5C, at PF in KEK. MA6-6 consists of six small second-stage anvils with an anvil guide and can be compressed by a cubic-anvil apparatus. ${ }^{8)}$ The anvil guide is made of tool steel (SUS304). The anvil guide has holes along one of the diagonal direction for access to the incident and exiting X-rays. Figure 6 shows an example of the cell assembly. ${ }^{4)}$ The sample container made of boron-epoxy or pyrophyllite is formed into a cube. The starting materials are put in a BN crucible. The crucible with a graphite heater is inserted in a cubic solid pressure medium. Pressure is determined by the lattice constant of the $\mathrm{NaCl}$ internal pressure marker.

\subsection{Thermoelectric measurement}

The thermoelectric measurement using the ZEM-3 equipment, a Seebeck coefficient and electric resistance measuring system made by ULVAC-RIKO, requires a larger length of more than $6 \mathrm{~mm}$ long. However, the typical size of the composite synthesized by the piston cylinder equipment shown in Fig. 1 was less than $5.0 \mathrm{~mm}$ in diameter. Therefore, it was necessary to develop the equipment of the thermoelectric measurement for the small composite. ${ }^{9)}$ Figure 7 shows a photograph of the measurement plates made of pyrophyllite. Four leads are wired on sample plate (a), and a sample is put on the leads indicated by the open circle. The interval between leads is $1 \mathrm{~mm}$; therefore, it is possible to measure a sample larger than $3 \mathrm{~mm}$. The cover plate consists of plates (b) and (c), and a thermocouple for measuring the temperature of the sample position and a differential thermocouple for the determining temperature gradient on the sample are wired along three grooves on plate (b). The sample is sandwiched between the cover plate and the sample plate and fixed by ceramic screws.

\section{Progress to explore thermoelectric materials}

In the following sections, research studies of the thermoelectric properties of skutterudites and magnesium silicide using the high-pressure synthesis method will be introduced. 


\subsection{Skutterudite}

Filled skutterudite compounds crystallize with a body-centered cubic structure of the space group $\operatorname{Im} \overline{3}\left(T_{h}^{5}\right.$, No. 204). ${ }^{10)}$ Their general formula is $R T_{4} X_{12}$, where $T=\mathrm{Fe}, \mathrm{Ru}$, and Os (site $8 \mathrm{c}$ ), $X=\mathrm{P}, \mathrm{As}$, and $\mathrm{Sb}$ (site $24 \mathrm{~g}$ ), and $R=$ alkaline earth, lanthanide, and actinide (site 2a). The $R$ ions are located inside oversized cages, formed by twelve $X$ ions, and undersized ions are believed to show random motion (rattling) around the equilibrium positions. ${ }^{11)}$ Thus, the rattling induces a marked phonon scattering, reducing the lattice thermal conductivity $\kappa_{\mathrm{L}}$. Owing to the reduced thermal conductivity, filled skutterudite compounds show excellent TE performance. ${ }^{12)}$ The skutterudite family includes binary, unfilled compounds with the same space group, which have the general formula $M X_{3}$ or $\square M_{4} X_{12}{ }^{13)}$ Here, $M=\mathrm{Co}, \mathrm{Rh}$, and Ir (site $8 \mathrm{c}$ ), $X=\mathrm{P}, \mathrm{As}$, and Sb (site $24 \mathrm{~g}$ ), and the symbol represents a vacancy (site 2a) inside the relatively large cages, formed by the $M$ and $X$ ions. This structure has eight formula units, including two voids, per cubic unit cell. The binary compound $\mathrm{CoSb}_{3}$ (or $\mathrm{Co}_{4} \mathrm{Sb}_{12}$ ) shows excellent TE properties (large Seebeck coefficient and high hole mobility). ${ }^{14)}$ Although the power factor $S^{2} \sigma$ of $\mathrm{CoSb}_{3}$ is quite large, the lattice thermal conductivity $\kappa_{\mathrm{L}}$ is still very high. The cage of $\mathrm{CoSb}_{3}$ can include guest ions without undergoing structural distortion. Therefore, a marked rattling effect is expected owing to the large vibration of guest ions located inside the cage. In fact, the vacancy can be partially occupied by rare-earth (RE) ions, such as $\mathrm{La}, \mathrm{Ce}$, and $\mathrm{Yb}$, or alkali-earth metal ions, such as $\mathrm{Ca}$ and $\mathrm{Ba}^{14-18)}$ It was reported that $\mathrm{CoSb}_{3}$ with $\mathrm{La}$ partial filling in its voids exhibits a large decrease in $\kappa_{\mathrm{L}}{ }^{14)}$ This suggests that the La ions filling in the voids also show a rattling effect. Furthermore, smaller and heavier ions should be more effective in inducing a rattling effect. Consequently, smaller and heavier RE atoms seem to be suitable for void fillers for $\mathrm{CoSb}_{3}$. However, only a few RE elements such as $\mathrm{La}, \mathrm{Ce}, \mathrm{Nd}$, $\mathrm{Eu}$, and $\mathrm{Yb}$ have been successfully inserted into the lattice voids of $\mathrm{CoSb}_{3}$ by conventional synthesis methods at ambient pressure. ${ }^{14-16,19,20)}$ Mei et al. have reported a systematic theoretical investigation of the filling fraction limit (FFL) of RE atoms in $\mathrm{CoSb}_{3}{ }^{21)}$ Their calculations reveal that the FFL decreases rapidly from $\mathrm{La}$ to $\mathrm{Sm}$, and becomes zero from $\mathrm{Gd}$ to $\mathrm{Lu}$, with the exception of Eu and $\mathrm{Yb}$ that exhibit relatively high FFLs of 0.44 for Eu and 0.30 for $\mathrm{Yb}$. The reasons for the relatively high FFLs of $\mathrm{Yb}$ and $\mathrm{Eu}$ are the low charge state of +2 of these elements in $\mathrm{CoSb}_{3}$ as compared with the charge state of the other $\mathrm{RE}$ atoms +3 . The effective charge state of the void filler is, therefore, an important factor in determining its FFL. High pressure benefits the entrance of heavier rare earths into the voids of the skutterudite structure than ambient pressure. The highest actual $\mathrm{Yb}$ doping 
ratio of 0.29 has been reported in the compound with the nominal composition $\mathrm{Yb}_{0.6} \mathrm{Co}_{4} \mathrm{Sb}_{12}$ (actual composition, $\mathrm{Yb}_{0.29} \mathrm{Co}_{4} \mathrm{Sb}_{12}$ ) synthesized under a pressure of $2 \mathrm{GPa}$ using a cubic-anvil-type apparatus. ${ }^{22)}$ The value is close to the theoretical FFL and the highest for any $\mathrm{Yb}_{x} \mathrm{Co}_{4} \mathrm{Sb}_{12}$ reported so far. The actual FFL of $\mathrm{Yb}$ was improved by the high-pressure synthesis technique. Figure 8 shows the temperature dependence of the lattice thermal conductivity $\kappa_{\mathrm{L}}$ for $\mathrm{Yb}_{x} \mathrm{Co}_{4} \mathrm{Sb}_{12}$ prepared under high pressure. ${ }^{20)} \kappa_{\mathrm{L}}$ decreases with increasing $\mathrm{Yb}$ filling ratio $x$. The lowest $\kappa_{\mathrm{L}}$ of $2.02 \mathrm{Wm}^{-1} \mathrm{~K}^{-1}$ was achieved in $\mathrm{Yb}_{0.29} \mathrm{Co}_{4} \mathrm{Sb}_{12}$ at room temperature. In highly $\mathrm{Yb}$-doped systems, however, the Seebeck coefficient of the compound decreases owing to its high electron concentration. To further optimize the figure of merit, excess electrons in $\mathrm{Yb}_{0.6} \mathrm{Co}_{4} \mathrm{Sb}_{12}$ need to be compensated for. The optimized Yb-filled and Fe-substituted compounds were synthesized at $2 \mathrm{GPa}$. The highest $Z T$ (0.11) was achieved for the nominal composition $\mathrm{Yb}_{0.6} \mathrm{Fe}_{0.5} \mathrm{Co}_{3.5} \mathrm{Sb}_{12}$ (actual composition, $\left.\mathrm{Yb}_{0.47} \mathrm{Fe}_{0.38} \mathrm{Co}_{3.62} \mathrm{Sb}_{12}\right)$ at $300 \mathrm{~K}{ }^{23)}$ This value is even higher than those of Ba- and $\mathrm{Yb}$ - double-filled Fe-substituted compounds $(Z T=0.05$ at $300 \mathrm{~K}$ and $Z T=0.6$ at $800 \mathrm{~K}){ }^{24)}$ Therefore, a higher $Z T$ in the compound could be achieved in the high-temperature range.

Recently, the use of rare-earth metals such as $\mathrm{Yb}$ has serious problems about cost and supply amount. Therefore, mischmetal $(\mathrm{Mm})$ has attracted much attention as the source of void-filling ions. $\mathrm{Mm}$ is an alloy of rare-earth elements in various naturally occurring proportions. Its typical composition includes approximately $50 \% \mathrm{Ce}$ and $25 \% \mathrm{La}$, with small amounts of $\mathrm{Nd}$ and $\mathrm{Pr}$. Mm is low-cost compared with individual rare earths because extraction processes are unnecessary. Furthermore, it was reported that the TE properties of double-filled $(\mathrm{Ce}, \mathrm{Yb})$ or multi-filled $(\mathrm{Ba}-\mathrm{La}-\mathrm{Yb})$ skutterudite were improved compared with those of single-filled skutterudite. ${ }^{25,}$ 26) Therefore, $\mathrm{Mm}_{x} \mathrm{Co}_{4} \mathrm{Sb}_{12}$ compounds are expected as high-performance and low-cost TE materials. Actually, partially Mm-filled skutterudite compounds $\mathrm{Mm}_{x} \mathrm{Co}_{4} \mathrm{Sb}_{12}$ were prepared at $4.5 \mathrm{GPa}$ and $873 \mathrm{~K}$ using a Kawai-type system. ${ }^{27)}$ Before the high-pressure synthesis, synthesis processes of the compounds at high pressures and high temperatures were investigated by in-situ X-ray diffraction measurements using synchrotron radiation and a cubic-anvil high-pressure apparatus at the beamline AR-NE5C at PF in KEK. ${ }^{6)}$ In a series of experiments, the optimum conditions for synthesizing the compounds under high pressure were decided. The partially Mm-filled skutterudite compound $\mathrm{Mm}_{0.6} \mathrm{Co}_{4} \mathrm{Sb}_{12}$ prepared under high pressure shows a relatively high $Z T$ of 0.25 at $700 \mathrm{~K}$ (Fig. 9). ${ }^{27)}$ The carrier concentration tuning by chemical doping could improve the performance of the compounds. 


\subsection{Magnesium silicide}

The TE material is remarkable as a material for the low-carbon society. When considering an in-vehicle exhaust heat power generation, a material with a high TE performance in the mid-temperature range (600-900 K) is sought. However, it includes toxic and rare elements such as $\mathrm{Bi}, \mathrm{Te}, \mathrm{Pb}, \mathrm{Co}$, and $\mathrm{Sb}$ in the composition element of the TE material with a high $Z T$ in this temperature region. ${ }^{28)}$ Therefore, these devices will be regulated in the future by the Regulation such as the Restriction of Hazardous Substances (RoHS) Directive, Registration, Evaluation, Authorization, and Restriction of Chemicals (REACH). Because silicide semiconductors such as $\beta-\mathrm{FeSi}_{2}, \mathrm{Mg}_{2} \mathrm{Si}, \mathrm{CrSi}_{2}$, and $\mathrm{MnSi}_{\sim 1.73}$ satisfy the above condition, TE materials have been studied since the 1960s. Recently, high-purity $\mathrm{Mg}_{2} \mathrm{Si}$ has been synthesized by Akasaka et al. ${ }^{29)}$ Consequently, research on the TE properties of $\mathrm{Mg}_{2} \mathrm{Si}$ as an environmentally friendly semiconductor has been accelerated. ${ }^{30-37)}$

The phase diagram of $\mathrm{Mg}_{2} \mathrm{Si}$ is shown in Fig. $10{ }^{38)}$ The melting points of $\mathrm{Mg}_{2} \mathrm{Si}$ and $\mathrm{Mg}$ are 1358 and $923 \mathrm{~K}$, respectively, and thus it is possible to synthesize from the $\mathrm{Mg}$-rich side. However, the unreacted Mg in the compound causes the degradation of the device by the oxidation of $\mathrm{Mg}$ in the high-temperature region. Furthermore, because the boiling point of $\mathrm{Mg}(1363 \mathrm{~K})$ is close to the melting point of $\mathrm{Mg}_{2} \mathrm{Si}$ in the high-temperature region, it is difficult to synthesize $\mathrm{Mg}_{2} \mathrm{Si}$ with a stoichiometric ratio without unreacted $\mathrm{Mg}$. In order to avoid the disagreement of stoichiometry and the oxidation of $\mathrm{Mg}$, high-pressure synthesis has been performed. The high-pressure technique can control the melting point, boiling point, synthetic temperature. The in-situ X-ray diffraction (XRD) study of the mixture of $\mathrm{Mg}$ and Si powders under high pressure has also been performed to determine the optimum conditions for the high-pressure synthesis of $\mathrm{Mg}_{2} \mathrm{Si}$. As a result of this high-pressure XRD experiment at $1 \mathrm{GPa}, \mathrm{Mg}_{2} \mathrm{Si}$ was synthesized at $573 \mathrm{~K}$. The synthetic temperature was lower than not only the melting points of $\mathrm{Mg}_{2} \mathrm{Si}, \mathrm{Mg}$, and $\mathrm{Si}$ but also the synthetic temperature for the atmospheric synthesis of $\mathrm{Mg}_{2} \mathrm{Si}$ using an electric furnace, which is $823 \mathrm{~K}$. It is considered that the decline in the synthesis temperature was caused by the high-pressure technique. A high-pressure synthesis of $\mathrm{Mg}_{2} \mathrm{Si}$ by a piston cylinder method was carried out at a pressure of $1 \mathrm{GPa}$ and a temperature of $673 \mathrm{~K}$. The Seebeck coefficient and electric resistance at high temperatures were measured for several cycles from 400 to $900 \mathrm{~K}$ to check the stability of the composite. The results of the Seebeck coefficients of the composite and another sample sintered under a relatively low pressure $(0.03 \mathrm{GPa})$ by spark plasma sintering (SPS) are shown in Fig. $11 .{ }^{9)}$ The absolute value of 
Seebeck coefficient of the composite was smaller than that of the latter. Furthermore, the electrical conductivity of the composite was smaller than that of the latter. In order to understand these decreases in the absolute values of both the Seebeck coefficient and electrical conductivity, the theoretical calculation of the pressure dependence of the lattice defect formation enthalpies was performed by first-principles calculations. ${ }^{39)}$ The calculation suggests that the decrease in the density of defects synthesized under pressure was caused by a low synthetic temperature, which is favorable for the relaxation of the $n$-type defect. As mentioned above, high-pressure synthesis is sensitive to the defect of the composite but can be used to synthesize new materials with different thermoelectric properties.

\section{Conclusions}

The use of a high-pressure technique that can control physical properties is effective for developing new functional materials. Using piston cylinder equipment and a multi-anvil apparatus, the high-pressure synthesis of new thermoelectric materials has been reviewed, and in-situ XRD analysis under high pressure and high temperature was introduced. The in-situ XRD technique is useful for determining the optimized synthetic conditions under high pressure. The TE performance is evaluated using $Z T$, which is a combination of the electrical conductivity, thermal conductivity, and Seebeck coefficient. These three thermal properties were changed by high-pressure synthesis. The TE performance parameters of skutterudites and magnesium silicide prepared under high pressure were estimated. For skutterudite compounds, RE atoms were inserted into large cages by high-pressure synthesis, then the TE performance was improved by reducing the lattice thermal conductivity by the rattling effect. On the other hand, $\mathrm{Mg}_{2} \mathrm{Si}$ compounds with a stoichiometric ratio were synthesized by controlling the melting and boiling points of materials by the high-pressure synthesis. The Seebeck coefficient and electrical conductivity of the compounds decreased more than those of the compound sintered by the SPS method. The decrease in the density of defects synthesized under pressure is expected by theoretical calculation. 


\section{Acknowledgments}

This work was performed using the facilities of the Institute for Solid State Physics, The University of Tokyo. This work was supported by JSPS KAKENHI Grant Numbers 23340092 and 26420731 and by the Adaptable and Seamless Technology transfer Program, JST Grant Number AS251Z01200L. This work was also supported by joint use of the facilities of the Institute for Planetary Materials, Okayama University. This work has been performed under the approval of the Photon Factory Program Advisory Committee (Proposal Nos. 2015G031, 2014G543, 2013G124, and 2012G566). 


\section{References}

1) D. M. Rowe, CRC Handbook of Thermoelectrics (CRC, Boca Raton, FL, 1995) Chap. 1.

2) G. J. Snyder and E. S. Toberer, Nat. Mater. 7, 105 (2008).

3) I. Shirotani, K. Takeda, C. Sekine, J. Hayashi, R. Nakada, K. Kihou, Y. Ohishi, and T. Yagi, Z. Naturforsch. B 61, 1471 (2006).

4) C. Sekine, Koatsuryoku no Kagaku to Gijutsu 16, 336 (2006) [in Japanese].

5) C. Sekine, T. Kawata, Y. Kawamura, and T. Yagi, J. Korean Phys. Soc. 63, 359 (2013).

6) C. Sekine, T. Kachi, T. Yoshida, R. Abe, T. Namiki, K. Akahira, and K. Ito, J. Phys.: Conf. Ser. 215, 012141 (2010).

7) C. Sekine, H. Kato, M. Kanazawa, Y. Kawamura, K. Takeda, M. Matsuda, K. Kihou, C.-H. Lee, and H. Gotou, J. Phys.: Conf. Ser. 502, 012017 (2014).

8) N. Nishiyama, Y. Wang, T. Sanehira, T. Irifune, and M. L. Rivers, High Pressure Res. 28, 307 (2008).

9) Y. Mori, Y. Kaihara, S. Nakamura, T. Yoshino, and K. Takarabe, Phys. Status Solidi C 10, 1847 (2013).

10) W. Jeitschko and D. Braun, Acta Crystallogr., Sect. B 33, 3401 (1977).

11) G. S. Nolas, D. T. Morelli, and T. M. Tritt, Annu. Rev. Mater. Sci. 29, 89 (1999).

12) B. C. Sales, D. Mandrus, and R. K. Williams, Science 272, 1325 (1996).

13) N. Mandel and J. Donohue, Acta Crystallogr., Sect. B 27, 2288 (1971).

14) G. S. Nolas, J. L. Cohn, and G. A. Slack, Phys. Rev. B 58, 164 (1998).

15) B. Chen, J. H. Xu, C. Uher, D. T. Morelli, G. P. Meisner, J. P. Fleurial, T. Caillat, and A. Borshchevsky, Phys. Rev. B 55, 1476 (1997).

16) J. Yang, Q. Hao, H. Wang, Y. Lan, Q. He, A. Minnich, D. Wang, J. Harriman, V. Varki, M. Dresselhaus, G. Chen, and Z. Ren, Phys. Rev. B 80, 115329 (2009).

17) M. Puyet, B. Lenoir, A. Dauscher, M. Dehmas, C. Stiewe, and E. Muller, J. Appl. Phys. 95, 4852 (2004).

18) L. D. Chen, T. Kawahara, X. F. Tang, T. Goto, T. Hirai, J. S. Dyck, W. Chen, and C. Uher, J. Appl. Phys. 90, 1864 (2001).

19) V. L. Kuznetsov, L. A. Kuznetsova, and D. M. Rowe, J. Phys.: Condens. Matter 15, 5035 (2003).

20) W. Jeitschko, A. J. Foecker, D. Paschke, M. V. Dewalsky, C. B. H. Evers, B. Kunnen, A. Lang, G. Kotzyba, U. C. Rodewald, and M. H. Möller, Z. Anorg. Allg. Chem. 626, 1112 (2000).

21) Z. G. Mei, W. Zhang, L. D. Chen, and J. Yang, Phys. Rev. B 74, 153202 (2006). 
22) Y. Chen, Y. Kawamura, J. Hayashi, and C. Sekine, Jpn. J. Appl. Phys. 54, 05550 (2015).

23) Y. Chen, Y. Kawamura, J. Hayashi, and C. Sekine, Jpn. J. Appl. Phys. 55, 04EJ02 (2016).

24) Y. Dong, P. Puneet, T. M. Tritt, and G. S. Nolas, J. Mater. Sci. 50, 34 (2015).

25) D. Bérardan, E. Alleno, C. Godart, M. Puyet, B. Lenoir, R. Lackner, E. Bauer, L. Girard, and D. Ravot, J. Appl. Phys. 98, 033710 (2005).

26) X. Shi, J. Yang, J. R. Salvador, M. Chi, J. Y. Cho, H. Wang, S. Bai, J. Yang, W. Zhang, and L. Chen, J. Am. Chem. Soc. 133, 7837 (2011).

27) C. Sekine, H. Kato, Y. Kawamura, and C.-H. Lee, Mater. Sci. Forum 879, 1737 (2017).

28) S. Fan, J. Zhao, J. Guo, Q. Yan, J. Ma, and H. H. Hng, Appl. Phys. Lett. 96, 182104 (2010).

29) M. Akasaka, T. Iida, J. Sato, K. Nishio, T. Takei, and Y. Takanashi, J. Cryst. Growth 304, 196 (2007).

30) T. Kajikawa, K. Shida, S. Sugihara, M. Ohmori, and T. Hirai, Proc. ICT’97, 1997, p. 275.

31) S. Battiston, S. Fiameni, M. Saleemi, S. Boldrini, A. Famengo, F. Agresti, M. Stingaciu, M. S. Toprak, M. Fabrizio, and S. Barison, J. Electron. Mater. 42, 1956 (2013).

32) C. Nakhowong, T. Sumpao, and T. Seetawan, Adv. Mater. Res. 802, 213 (2013).

33) G. Fu, L. Zuo, J. Longtin, C. Nie, and R. Gambino, J. Appl. Phys. 114, 144905 (2013).

34) T. Sakamoto, T. Iida, S. Kurosaki, K. Yano, H. Taguchi, K. Nishio, and Y. Takanashi, J. Electron. Mater. 40, 629 (2011).

35) T. Sakamoto, T. Iida, A. Matsumoto, Y. Honda, T. Nemoto, J. Sato, T. Nakajima, H. Taguchi, and Y. Takanashi, J. Electron. Mater. 39, 1708 (2010).

36) S. Fiameni, S. Battiston, S. Boldrini, A. Famengo, F. Agresti, S. Barison, and M. Fabrizio, J. Solid State Chem. 193, 142 (2012).

37) S.-W. You, K.-H. Park, I.-H. Kim, S.-M. Choi, W.-S. Seo, and S.-U. Kim, J. Electron. Mater. 41, 1675 (2012).

38) Binary Alloy Phase Diagrams ed. T. B. Massalski, H. Okamoto, P. R. Subramanian, and L. Kacprzak (American Society for Metals, Metals Park, OH, 1990) 2nd ed., p. 2548.

39) Y. Imai, Y. Mori, S. Nakamura, and K. Takarabe, J. Alloys Compd. 664, 369 (2016). 


\section{Figure Captions}

Fig. 1. Cell assembly for piston cylinder high-pressure apparatus.

Fig. 2. High-pressure apparatus (a) with the guide block and (b) installed at Muroran Institute of Technology. ${ }^{4)}$

Fig. 3. Cell assembly for cubic anvil high-pressure apparatus. ${ }^{4)}$

Fig. 4. Kawai-type high-pressure apparatus (a) with the guide block and (b) installed at Muroran Institute of Technology. ${ }^{4)}$

Fig. 5. Cell assembly for Kawai-type high-pressure apparatus. ${ }^{4)}$

Fig. 6. Cell assembly for in situ X-ray experiments. ${ }^{4)}$

Fig. 7. Photograph of measurement plate made of pyrophyllite for the thermoelectric measurements at high temperature. Four leads are wired on the sample plate (a), and the sample is put in the open circle. The cover plate consists of (b) and (c), and a sample is fixed between the cover plate and the sample by ceramic screws. ${ }^{9)}$

Fig. 8. (Color online) Lattice thermal conductivity $\kappa_{\mathrm{L}}$ of $\mathrm{Yb}_{x} \mathrm{Co}_{4} \mathrm{Sb}_{12}$ prepared under high pressure. ${ }^{22)}$

Fig. 9. Temperature dependence of dimensionless figure of merit $Z T$ for $\mathrm{Mm}_{0.6} \mathrm{Co}_{4} \mathrm{Sb}_{12}$ prepared under high pressure in high-temperature region. ${ }^{27)}$

Fig. 10. Phase diagram of $\mathrm{Mg}_{2} \mathrm{Si}$. The melting point of $\mathrm{Mg}_{2} \mathrm{Si}$ is $1358 \mathrm{~K}$, which is close to the boiling point of $\mathrm{Mg}$ in the high-temperature region. ${ }^{38)}$

Fig. 11. Seebeck coefficients of $\mathrm{Mg}_{2} \mathrm{Si}$ synthesized under pressure and sintered by SPS 
method. The absolute value of the Seebeck coefficient was decreased by high-pressure synthesis. ${ }^{9)}$ 


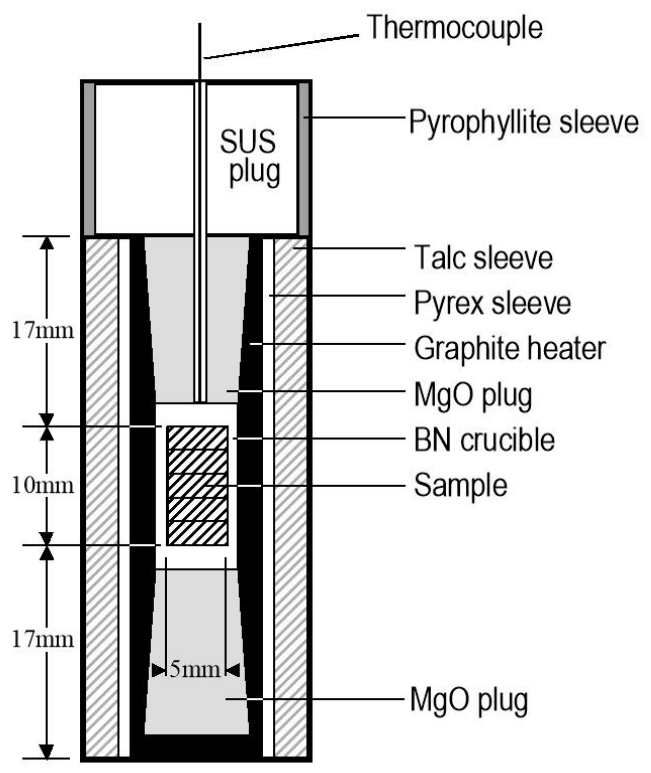

Fig. 1 


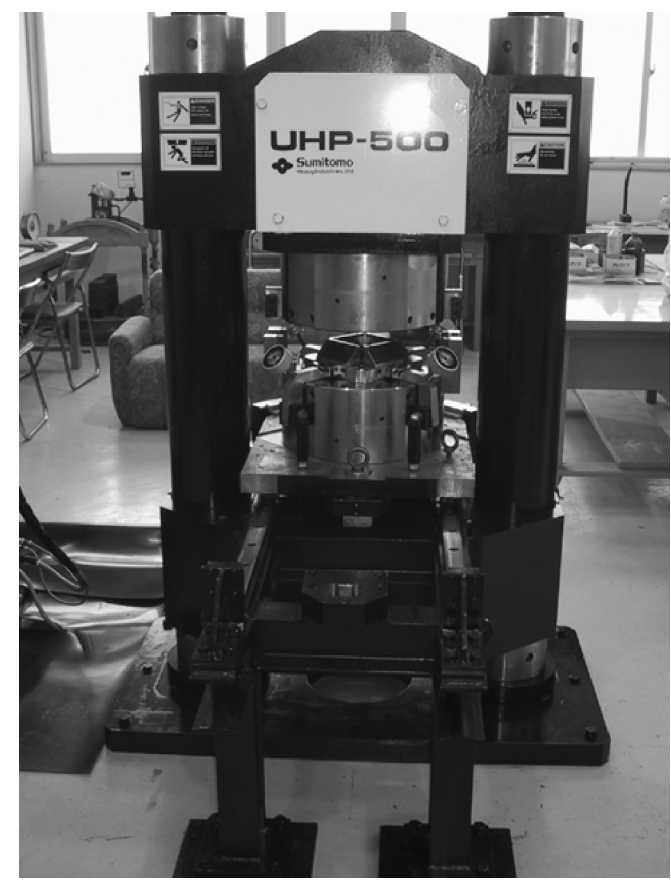

(a)

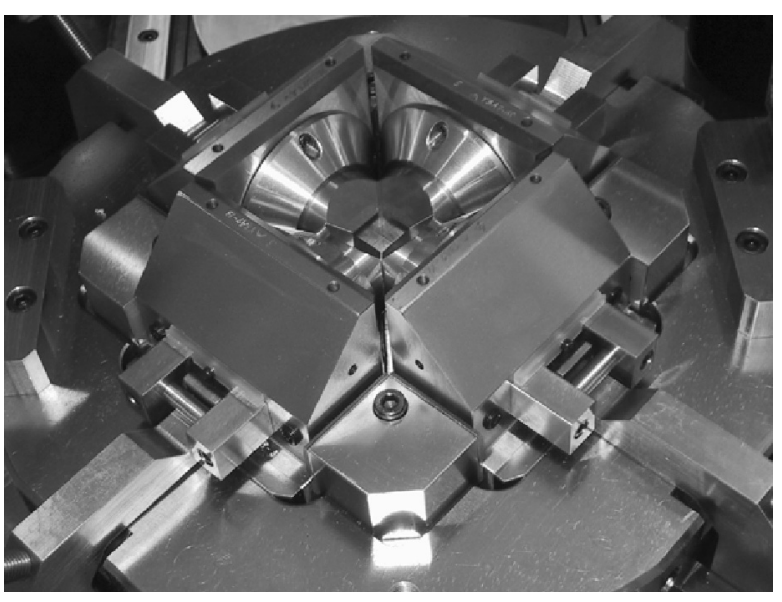

(b)

Fig. 2 


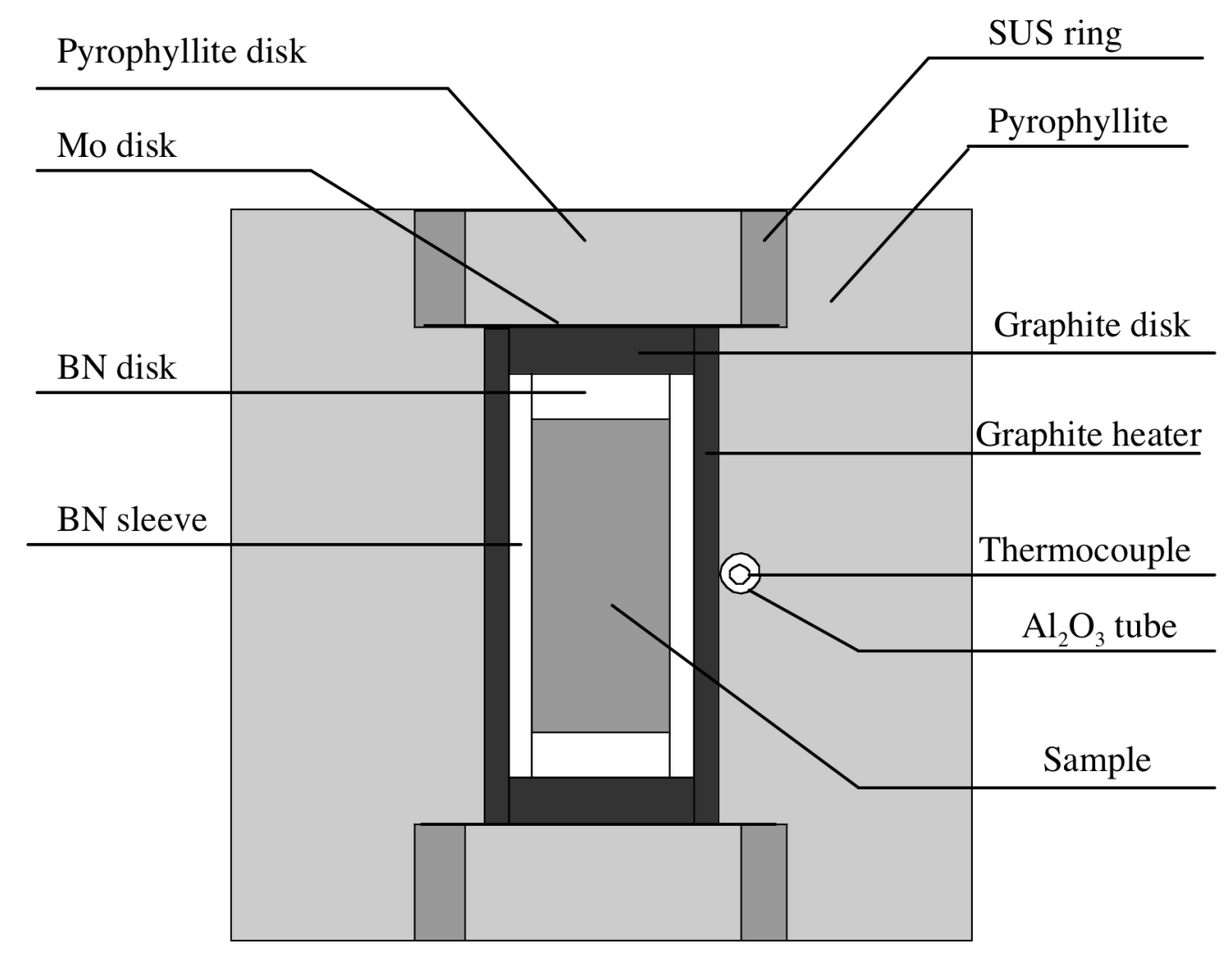

Fig. 3 


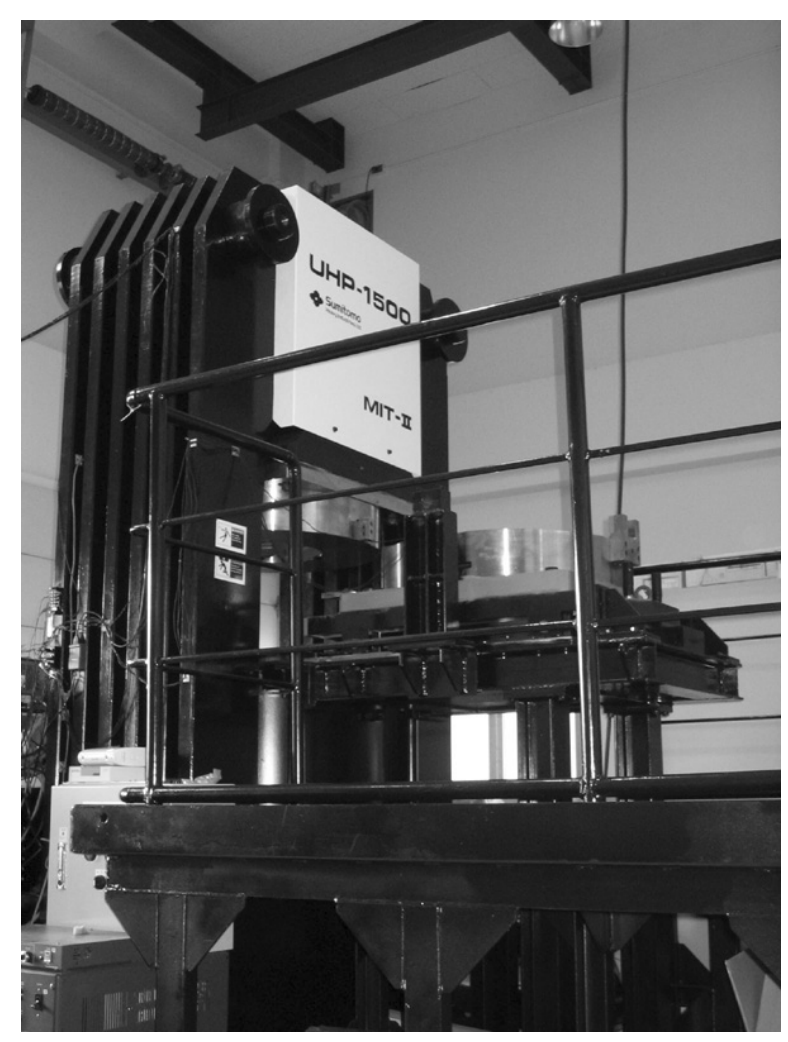

(a)

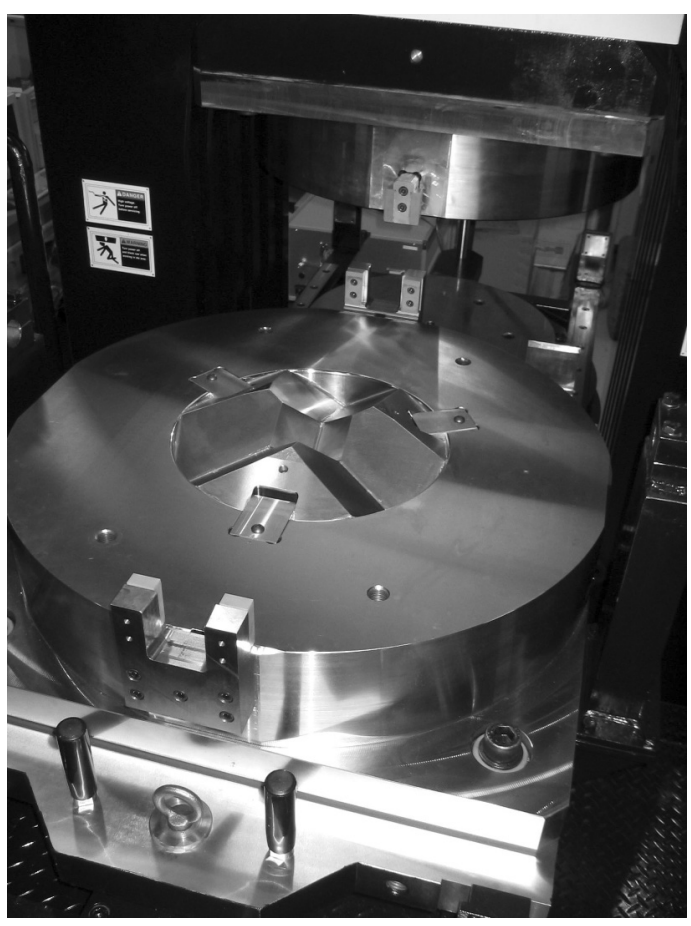

(b)

Fig. 4 


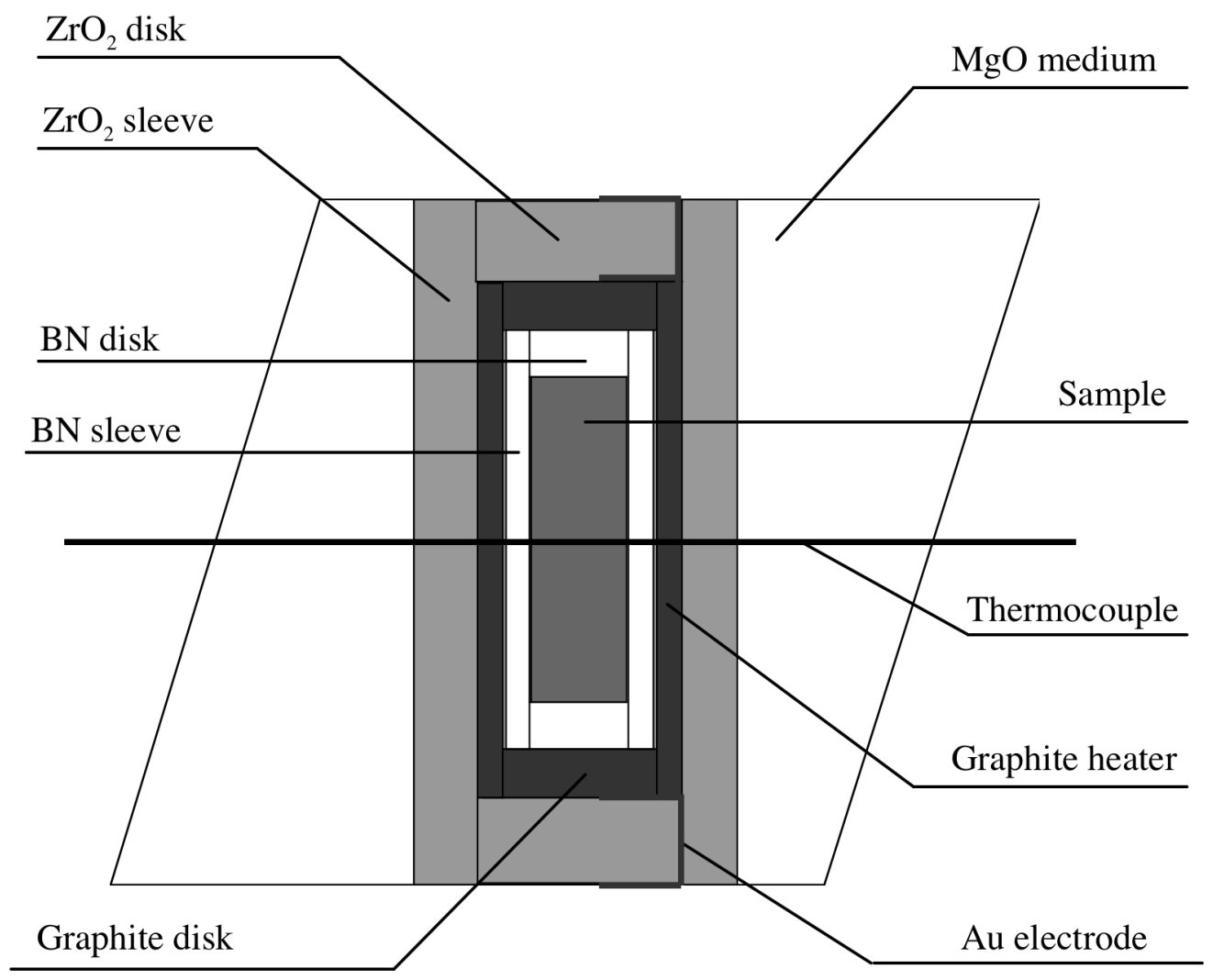

Fig. 5 


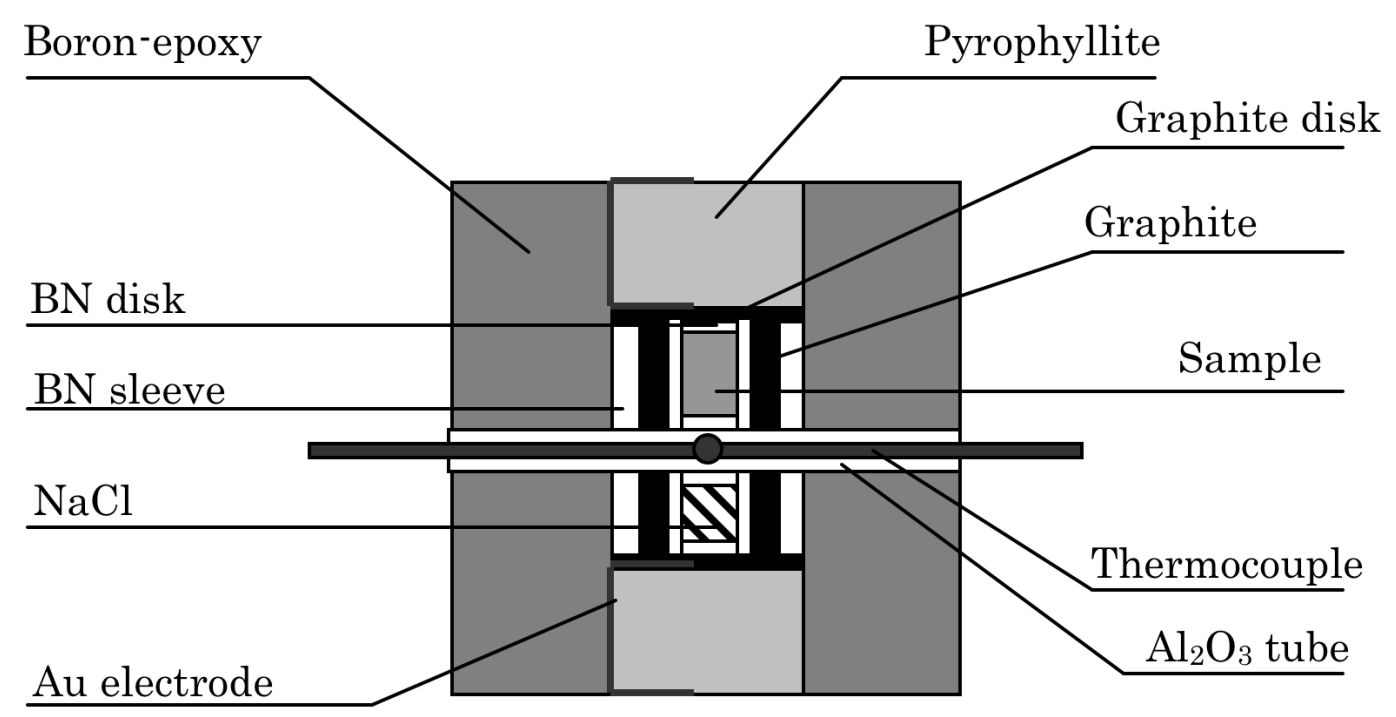

Fig. 6 


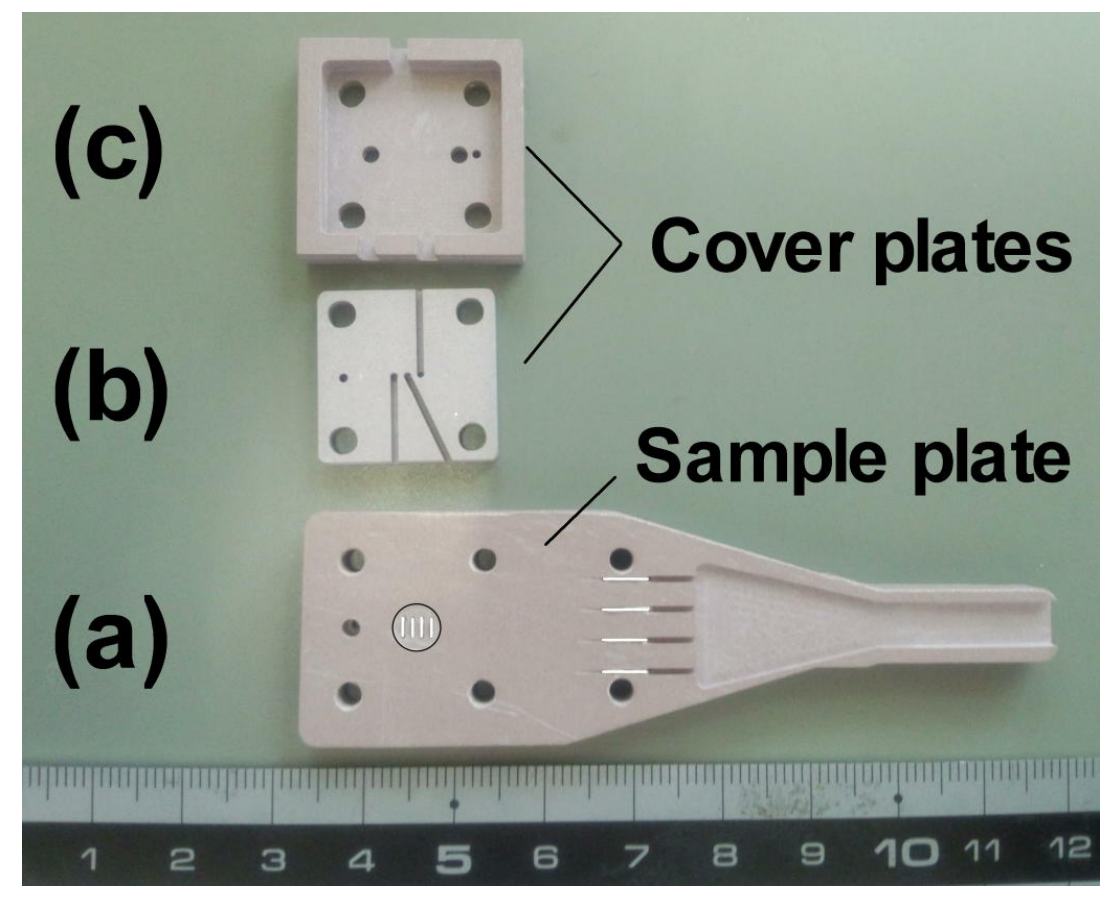

Fig. 7 


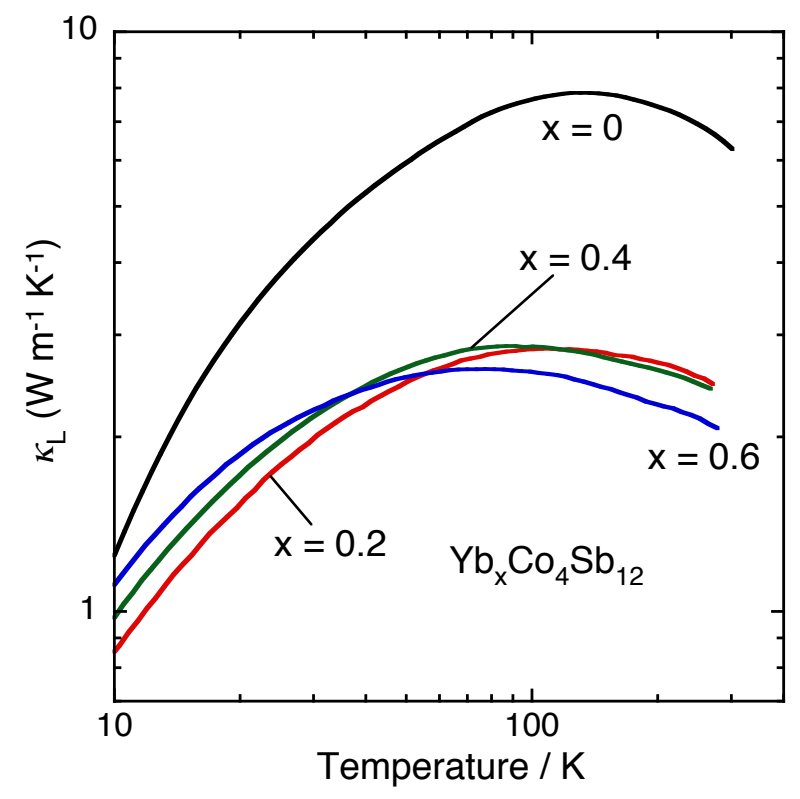

Fig.8 (Color Online) 


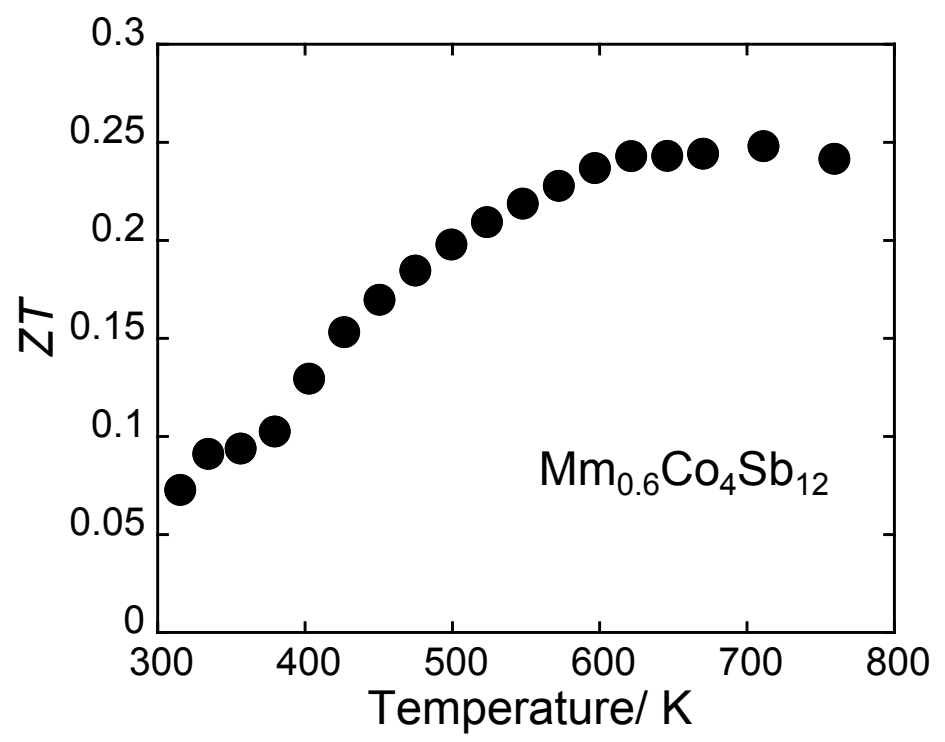

Fig. 9 


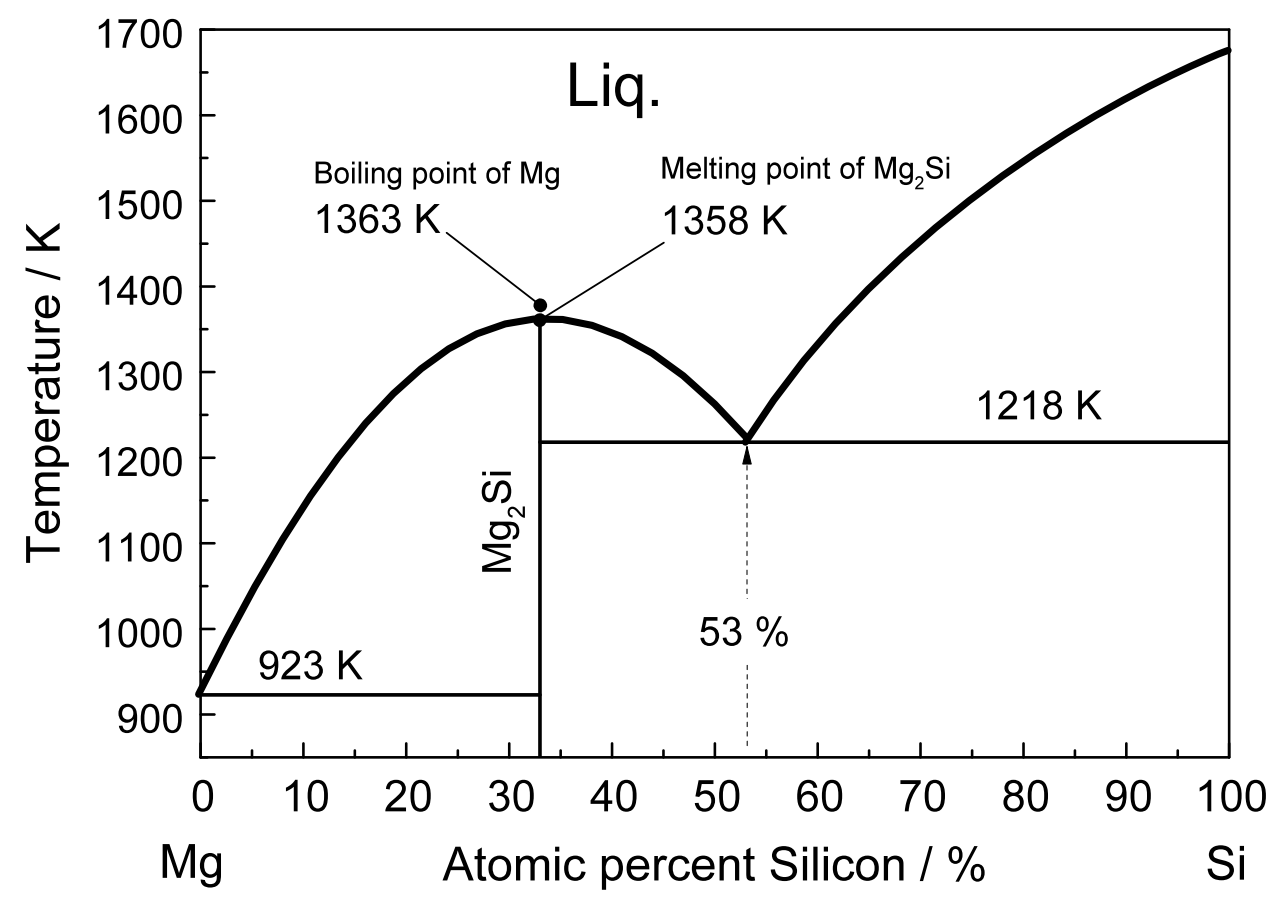

Fig. 10 


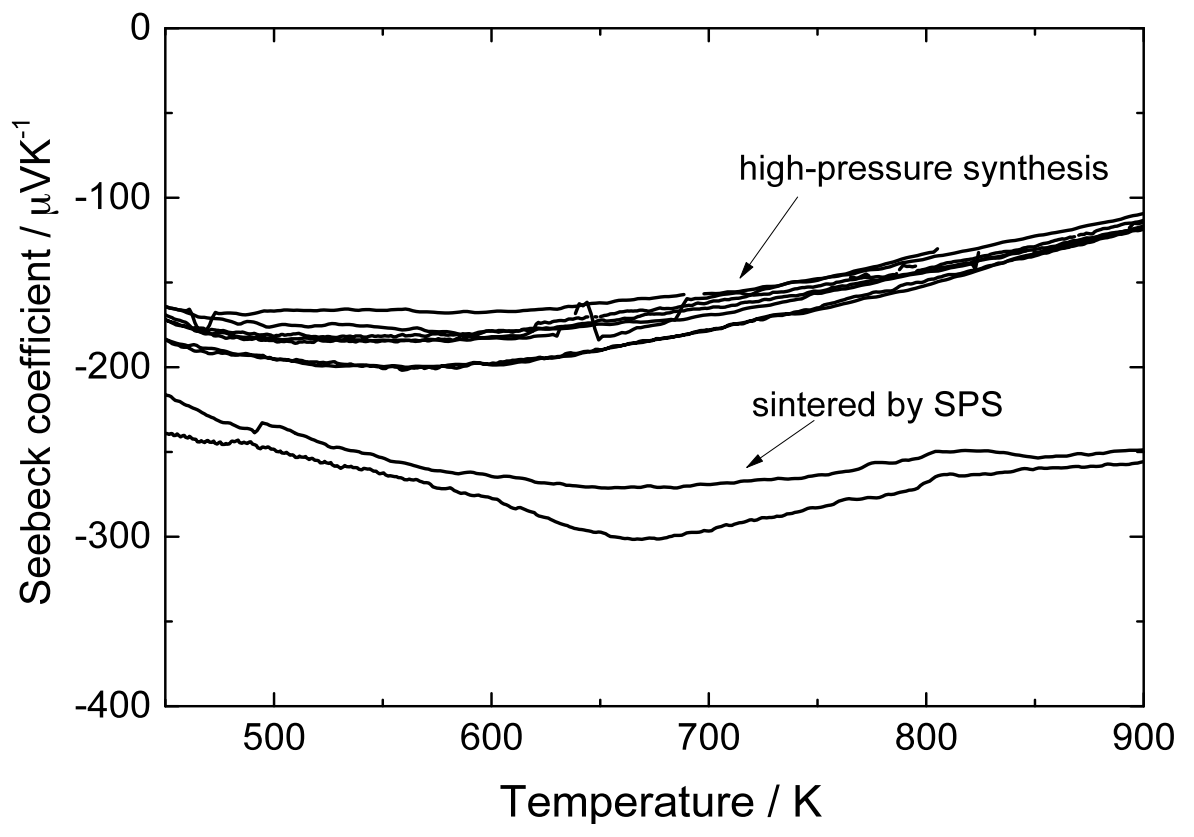

Fig. 11 